\title{
Exploring the Use of Discussion Strategies and Labels in Asynchronous Online Discussion
}

\author{
Fei Gao \\ Bowling Green State University
}

\begin{abstract}
Drawing on research in constrained online discussion environments and strategy instruction, this approach combines explicit instruction on discussion strategies with the use of post type labels. In a trial of this approach in an online course, students actively used the discussion strategies and post type labels in their discussions. Analysis of student posts and survey responses suggested that students in the experimental group used discussion strategies more frequently after the intervention as compared to the control group and perceived that this approach positively impacted their discussions. In addition, there was a certain degree of improvement in the quality of discussion as measured by Gunawardena, Lowe, and Anderson's (1997) critical analysis model.
\end{abstract}

\section{Introduction}

Asynchronous online discussion has become one of the major means of supporting student learning in online environments (Joeng, 2003; J. Thomas, 2013). Researchers believe that asynchronous online discussion forums could provide ideal environments for the social constructivist mode of learning, where the learners actively and continuously negotiate and construct meanings in the social context (Jonassen, 1991; Kanuka \& Anderson, 1998; Oztok, Zingaro, Brett, \& Hewitt, 2013). More specifically, asynchronous online discussion forums support a more decentralized and collaborative learning environment, where the teacher acts as a facilitator, and students take responsibility for their own learning (Jonassen, Davidson, Collins, Compbell, \& Hagg, 1995). In addition, online discussion tools automatically keep written records of the discussion, providing learners more opportunities to identify, examine, and make connections between ideas. Asynchronous discussion also frees learners from time and space constraints, providing more time for reflection and increasing the chances that in-depth thinking will occur (Anderson, 1996; Collison, Elbaum, Haavind, \& Tinker, 2000).

Discussion in online courses, however, typically falls short of this ideal (Rourke \& Kanuka, 2009). Students participating in asynchronous online discussion do not automatically interact to construct knowledge (An, Shin, \& Lim, 2009; M. J. W. Thomas, 2002), and they make limited efforts to extend and 
deepen the conversation by building upon others' ideas (Hara, Bonk, \& Angeli, 2000; Larson \& Keiper, 2002). The focus of online discussion, therefore, often remains at surface levels, such as sharing or comparing information, seldom delving to deeper levels that involve negotiating meanings, synthesizing or applying newly acquired knowledge (Davidson-Shivers, Luyegu, \& Kimble, 2012; Gunawardena et al., 1997; Moore \& Marra, 2005; Wegmann \& McCauley, 2008).

To solve the problem of lack of quality student participation in online discussions, researchers have explored and experimented with a number of different approaches, including developing online activities to engage learners (Ertmer et al., 2007; Nussbaum, 2005; Seo, 2007), providing participation guidelines and expectations (Gilbert \& Dabbagh, 2005), teaching and modeling ways of interaction (H. J. Choi \& Johnson, 2005; Yang, Newby, \& Bill, 2005; Zydney, deNoyelles, \& Seo, 2012), enhancing instructor's or moderator's facilitation (Berge \& Muilenburg, 2002; Bradley, Thom, Hayes, \& Hay, 2008), and designing constrained discussion environments by adding specific features to the discussion forums to increase the likelihood of effective discussions (Guzdial \& Turns, 2000; Jonassen \& Kim, 2010). This study is another effort to address the common problems in online discussions. Building upon previous research on constrained discussion environments, the study examines the effectiveness of teaching students using discussion strategies in a constrained online discussion environment. More specifically, students received explicit instruction on how to effectively use five discussion strategies during online discussions and were asked to use post type labels built into the constrained discussion environment to structure their posts. The purpose of the study is to find out how the approach affected student participation in the online discussion.

\section{Literature Review}

\section{Constrained Online Discussion Environments}

Concerned about the lack of quality participation from students in online discussion, researchers have designed constrained discussion environments to scaffold the process of online discussion. A constrained environment is a pre-structured form of discussion environment that guides learners to participate in the discussion in certain ways. Typically, it requires learners to start their notes with a predefined phase (a post starter, such as "My argument is") or label their notes using a predefined set of post types, such as evidence or elaboration (Jonassen \& Kim, 2010; Oh \& Jonassen, 2007). The rationale is that such structured environments can promote learners' metacognitive thinking and engage them in desired cognitive processes (Jonassen \& Remidez, 2005; Scardamalia \& Bereiter, 1994).

Constrained discussion environments have been examined by a number of researchers to determine their effectiveness. Nussbaum and colleagues (2004), for example, encouraged counterargument using a constrained environment, in which students were asked to choose from a dropdown menu a post starter, such as "On the opposite side," "I need to understand," or "My argument is," to begin their notes. By comparing discussion in this environment with that in a threaded forum, they concluded the approach significantly increased the frequency of disagreement but was not equally effective for all types of learners. The approach was particularly useful for students with low degrees of curiosity or assertiveness. In another study, Chiu and colleagues (2013) examined whether such a constrained environment could be used to enhance fifth-grade students' communicative competence and collaborative productivity. They found that students who used a predetermined phrase from a list of utterance patterns to structure their posts had significantly better communicative competence development than those in the unstructured condition. Students in the structured environment also continued to demonstrate better collaborative productivity.

In addition to post starters, some researchers designed environments where participants were required to add a post type label adjacent to the titles of their posts. The SpeakEasy environment 
introduced by Hoadley and Linn (2000), for example, allows students to use semantic labels such as and, or, but, i.e., and ? to indicate the relationship of a current post to previous posts. During the discussion, students were prompted to categorize their comments by picking a semantic label before providing a subject heading. When comparing student discussions in SpeakEasy with those in a regular threaded forum, they found no significant difference. Students in both discussion formats gained an integrated understanding of the learning content. Research on constrained environments, however, has led to inconsistent findings. In the constrained environment developed by Oh and Jonassen (2007), post type labels (which are hypothesis cause, solution generation, verification, rebuttal, evidence, and elaboration) and post starters (including "My experience is," "I believe," "Research shows," and "A scholar says") were applied. After comparing the online argumentation that occurred in this environment with that in a threaded forum, Oh and Jonassen concluded that participants in the constrained environment generated more evidence posts, and more hypothesis and hypothesis testing posts. Similarly, Scheuer and colleagues' (2013) study suggested that when students used a combination of post starters and argument diagramming, where students chose among four boxes with distinctive colors ("main thesis," "main argument," "helping argument," and "fact") to indicate different post types, they posted more elaborative comments and had a more positive attitude toward the learning experience. The study conducted by Jeong and Joung (2007), however, reported negative effects of using such labels. The researchers compared the nature of online argumentation of three groups: (a) control group; (b) constraints-only group, where students posted only specific types of message from a prescribed set of message categories, such as arguments, evidence, critique, and explanation; and (c) constrained-with-labels group, where students posted specific types of messages and at the same time manually labeled each message with a prescribed post type label. The study found that participants in the constrained-with-labels group were less likely to critique others and respond to critiques than the other two groups, suggesting that post type labels might inhibit the process of developing deeper and more critical analysis of individual arguments.

In addition to examining the change of quality in student discussion, other effects of constrained environments were also studied. For example, Tsai and Tsai (2013) explored the effects of the constrained environment on student conceptions of and approach to online argumentation. The study revealed that students with fragmented conceptions of argumentation tended to employ a surface approach during the discussion despite the use of post type labels and question prompts. However, those students tended to develop potentially deeper approaches than those who did not used question prompts. In sum, though using post type labels and post starters seems to be a promising approach to improve the quality of online discussion, the findings are rather mixed and inconclusive. In addition, most constrained environments were designed to enhance student argumentative skills, but little is known about how such environments can be used to benefit online discussions that are not argumentative in nature.

\section{Learning Strategy Instruction}

It is assumed that people regulate and control their learning by choosing the learning strategy that seems to be most suitable for dealing with the learning task. Rooted in cognitive psychology, learning strategy is defined as "behaviors and thoughts that a learner engages in during learning and that are intended to influence the learner's encoding process” (Weinstein \& Mayer, 1986, p. 315). It has two key components: (a) cognitive processes used to complete the task at hand and (b) metacognitive processes used to select a strategy for the task, monitor the success of the chosen strategy, and evaluate the outcome of using the strategy (Schumaker \& Deshler, 2006).

An extensive body of research has shown that the strategy instruction is effective for improving reading and learning (Brown, Pressley, Van Meter, \& Schuder, 1996; Chamot, 2005; Deshler \& Schumaker, 1988; Deshler, Schumaker, Lenz, \& Ellis, 1984; Duffy \& Roehler, 1987, 1989; Graham, 2006; King, 1991; Palinscar \& Brown, 1984; Pressley, 1986; Pressley, Wood, Woloshyn, \& Martin, 1992). Recently, some researchers have also examined the feasibility of learning strategy instruction in adult education settings, and have suggested that learning strategy instruction might have a positive impact on 
the instructor-learner interaction (Mellard, 2006) and potentially help less successful learners perform better (Hock \& Mellard, 2011; MacArthur \& Lembo, 2009).

According to Pressley and Woloshyn (1990), though the way the strategies were taught varies significantly, effective strategy instruction shares the following fundamental principles:

Teacher modeling. The teacher describes the strategy to students by providing metacognitive information such as what the strategy is, why the strategy should be used, and when and where it should be used. The teacher then models the use of the strategies.

Guided practice and feedback. Students spend ample time practicing the strategy under the teacher's guidance. The teacher provides scaffolding as well as feedback regarding how to improve the execution of the strategy. Practice usually begins with fairly simple tasks and then moves to more complex tasks.

Gradual increase in students' responsibility. Students take more and more responsibility in using the strategy. The ultimate goal is that students use the strategies appropriately, skillfully, and autonomously.

These three principles thus guided the design of online discussion strategy instruction in this study.

\section{Five Online Discussion Strategies}

Based on the literature on both constrained discussion environment and learning strategy instruction, an alternative approach that combined the use of labels with strategy instruction was proposed to improve the quality of online discussion, and a quasi-experimental study was conducted to understand the effectiveness of this approach.

Five discussion strategies were developed. The first four strategies were selected based on the productive discussion model (Gao, Wang, \& Sun, 2009). According to Gao and the colleagues (2009), in a productive discussion, learners should demonstrate the following dispositions: (a) discuss to comprehend, where learners engage in cognitive processes such as interpretation, elaboration, and making connections; (b) discuss to critique, where learners critically examine other people's views and are analytical to conflicting views; and (c) discuss to construct knowledge, where learners negotiate meanings and reconsider and refine previous thinking. As a result, the following four strategies were chosen to support each of the dispositions: elaborating and clarifying (Disposition 1), making connections (Disposition 1), challenging others' views (Disposition 2), and building upon others' views (Disposition 3). Questioning was added as the fifth strategy, because peer questioning has always been considered as an important strategy to improve the quality of small group discourse in face-to-face environments (Brookfield \& Preskill, 1999; Dillon, 1984; King, 1990, 1991; King \& Rosenshine, 1993), and a number of researchers suggest that peer questioning has the potential to improve the quality of peer interaction in online discussions (I. Choi, Land, \& Turgeon, 2008; I. Choi, Land, \& Turgeon, 2005; Johnson, 2006), though its effectiveness has not been thoroughly explored. Table 1 presents the five online discussion strategies to be taught to the students. It is assumed that teaching students these strategies would prompt students to use these strategies more frequently when having online discussions.

Table 1 Five Online Discussion Strategies

\begin{tabular}{|l|l|}
\hline Strategies & Definitions \\
\hline Elaborating and clarifying & Support an argument with evidence or details \\
\hline Making connections & Connect discussion to other pieces of arguments or resources \\
\hline Challenging others' views & Suggest a different or contradictory perspective \\
\hline Building upon others'views & Build upon and further develop others' perspectives \\
\hline Questioning & Raise questions to move the discussion forward \\
\hline
\end{tabular}




\section{Research Questions}

The proposed approach combined explicit instruction on the five discussion strategies with the use of post type labels. To examine the effects of this approach on student discussion, a quasi-experimental study was conducted in an online master's-level course in educational psychology. The students in Section B served as the experimental group and received the intervention. More specifically, in Section B, the instructor provided explicit instruction on the five strategies. Then, in the discussion forums, students in Section B were required to label their posts with post types indicating the strategies used: (a) elaborating and clarifying (EC), (b) making connections (MC), (c) challenging (CH), (d) building (BLD), and (e) questioning (QST). The discussions generated by students in Section B were then compared to those generated by students in Section A of the same course, where no strategy instruction or post type labels were provided. The exploratory study focused on the following questions:

1. Did students in Section B use the discussion labels and strategies more frequently in their discussion as compared to students in Section A?

2. Did the approach affect the overall quality of the discussion?

3. How did students perceive the impact of this approach on their discussion and learning?

\section{Method}

\section{Participants and Setting}

The research participants were students from two different sections of a master's-level online course in educational psychology. Twenty-two students in Section A served as the control group, and 17 students in Section B served as the experimental group. Most of the students (around 70\%) in both sections were K-12 teachers, and the rest (around 30\%) were nursing students. The majority of students in the study (28 out of 39 ) were females. Both sections were taught by the same instructor.

This online course contained a one-week introduction unit and four learning modules. In the introduction unit, students read an article on the classical learning theories of Plato and John Locke, and had discussions about the two learning theories. In each of the four subsequent two-week modules, students were required to read articles on one particular educational theory and participate in the online discussion within a small group of three to five members responding to questions posted by the instructor. The purpose of the discussions was to have students connect the readings to their own experiences so as to develop a deeper and more nuanced understanding of the learning theories. Here is a typical example of the discussion questions: "Find an example from your work or from elsewhere that might be an example of the idea that 'what were once mistakes are now alternative conceptions.' Describe the example and make it clear how it illustrates some of the important qualities of the constructivist perspective on learning." All online discussions in the introduction unit as well as in the modules were held in the threaded online discussion forums.

\section{Procedures}

In each module of the class, students first completed two or three readings on a particular educational theory and then responded to the instructor's question based on what they had learned from the readings. The instructor observed the discussions and only stepped in occasionally to point out misunderstandings or to redirect the discussions to important issues.

All the content and activities were the same for both sections except that students in Section B were instructed to use discussion strategies and post types from Module 1 to Module 3 . The introduction unit served as a baseline for comparing the discussions across the two sections. In Section B, the instructor introduced one or two discussion strategies every module before the discussions, and students were asked to use the strategies they had learned along with corresponding post type labels in their 
discussions.

More specifically, for each strategy, the instructor provided a written mini-lecture explaining what the strategy is and how it should be used. Appendix 1 provides an example of how these strategies were taught. At the end of each module, the instructor selected a few good examples from the student discussions demonstrating good use of strategies, and provided general feedback to the whole class as to how well they used the strategies in the discussions. By the end of Module 3, all five strategies had been taught. Students continued using the strategies and labels in the last module. The instructor monitored the discussions but provided no scaffolding or feedback unless discussion groups overlooked, misinterpreted, or struggled with certain learning tasks.

The intervention lasted for six weeks (from Module 1 to Module 3). Altogether, the instructor taught five strategies to the students in Section B. Clarifying and elaborating and making connections in Module 1, challenging and building in Module 2, and questioning in Module 3. In Module 4, which was the final two weeks of the course, no new discussion strategy was introduced. Students in Section B were asked to continue using the strategies and labels in their discussions.

Throughout the class, students in Section B had access to an online forum where they could write about their experiences of using discussion strategies and labels. Participation in this online forum was completely voluntary. At the end of the semester, students in Section B completed a survey on their experiences of learning and using discussion strategies and labels. This survey was composed of 10 Likert-scale items with five answer choices ranging from strongly disagree to strongly agree.

\section{Data Analysis}

Student online posts in both sections were analyzed and compared, and the survey responses were used to triangulate the results of the post analysis.

\section{Online posts}

The number of post type labels used by the students in the final module was calculated. Then, the types of strategies present in each post in the introduction week and the final module were identified. When more than one strategy was evident in one post, all of them were coded. The number of individual strategies used was counted based on the coding. Two trained coders independently coded all the posts. Their coding was considered as an agreement only when the number and the type of the strategies they identified were exactly the same. For example, if one coder identified three strategies on a post and the other identified two of the three, it was counted as a disagreement rather than an agreement. The percentage of agreement was $71.1 \%$, and the Cohen's kappa was .56. According to Capozzoli and colleagues (1999), a Cohen's kappa between .40 to .75 indicates fair-to-good agreement beyond chance.

Finally, to determine the overall quality of the discussions, students' posts were analyzed using Gunawardena et al.'s interaction analysis model (see Table 2). This particular model was chosen for two reasons. First, the purpose of this model is to identify the different phases of knowledge construction in online discussions. The adoption of this model may help the researchers understand the processes of how meaning is negotiated and how knowledge is constructed collaboratively in such online discussions.

Second, the model has been widely used by researchers for understanding and assessing online discussions (Kanuka \& Anderson, 1998; Moore \& Marra, 2005; Yang et al., 2005) and, thus, allows for comparison of the quality of discussions in this study with those in other studies. Two coders independently coded all the posts, and one post could be coded under multiple categories (Gunawardena, et al., 1997). The coding reached a Cohen's kappa of .76, with $83.8 \%$ of the units coded exactly the same. Disagreements were resolved through discussion. 
Table 2 Gunawardena, Lowe, and Anderson's (1997) Interaction Analysis Model

\begin{tabular}{|l}
\hline Phase I: Sharing/comparing of information \\
A. A statement of observation or opinion \\
B. A statement of agreement from one or more other participants \\
C. Corroborating examples provided by one or more participants \\
D. Asking and answering questions to clarify details of statements \\
E. Definition, description, or identification of a problem
\end{tabular}

\section{Phase II: The discovery and exploration of dissonance or inconsistency} among ideas, concepts, or statements
A. Identifying and stating areas of disagreement
B. Asking and answering questions to clarify the source and extent of disagreement
C. Restating the participant's position, and possibly advancing arguments or considerations in its support by references to the participant's experience, literature, formal data collected, or proposal of relevant metaphor or analogy to illustrate point of view
Phase III: Negotiation of meaning/co-construction of knowledge
A. Negotiation or clarification of the meaning of terms
B. Negotiation of the relative weight to be assigned to types of argument
D. Proposal and negotiation of new statements embodying compromise, co- construction
C. Identification of areas of agreement or overlap among conflicting concepts
E. Proposal of integrating or accommodating metaphors or analogies

\section{Phase IV: Testing and modification of proposed synthesis or co-construction}
A. Testing the proposed synthesis against "received fact" as shared by the participants and/or their culture
B. Testing against existing cognitive schema
C. Testing against personal experience
D. Testing against formal data collected
E. Testing against contradictory testimony in the literature

\section{Phase V: Agreement statement(s)/applications of newly-constructed meaning}
A. Summarization of agreement(s)
B. Applications of new knowledge
C. Metacognitive statements by the participants illustrating their understanding that their knowledge or ways of thinking (cognitive schema) have changed as a result of the conference interaction

No significant difference was found between the two sections in the introduction unit in terms of the frequencies of strategy use and the number of posts under the five phases of the interaction analysis 
model. As a result, a multivariate analysis of variance (MANOVA) was conducted to determine the magnitude of differences in student behaviors in the final module.

\section{Survey}

The survey contained 10 Likert-scale questions, each with five responses from strongly disagree to strongly agree (coded as -2, -1, 0, 1, 2 respectively). A positive number suggested a positive effect of the approach. Student responses were examined to see if there was any extreme answering pattern (e.g., providing responses of only strongly disagree and strongly agree), which could emotionally obscure the precision of the answers, and no extreme patterns were identified. Finally, MANOVA was used to determine whether the means of student responses to the 10 Likert-scale questions were significantly higher than zero.

\section{Student online comments}

As mentioned in the procedures section, students in Section B wrote on a separate online forum throughout the course about their experiences of receiving discussion strategy instruction and having online discussions using strategies and labels. This is not a formal data source, and students were not required to make a comment. But the data were analyzed because of their potential to offer additional insights to answer the research questions. Two coders worked together and identified three major themes that emerged from students' comments. Then, they worked independently to code all the comments into the three categories. The interrater agreement was $85.2 \%$, and the differences were resolved through discussion.

\section{Results}

To address the first research question concerning the extent to which students used the discussion strategies and labels in the discussions, students' use of the post type labels and discussion strategies were examined.

\section{Student Use of Post Type Labels}

Table 3 presents how the students in Section B used the five labels during the final module. Students used labels in 54 posts, approximately $60 \%$ of the total posts. All but two students labeled at least one of their posts. The labels chosen by students, however, did not always reflect the actual content of the post, as judged by the independent coders. For example, only 64\% (9 out of 14) of the posts labeled building were considered to be correctly labeled, and most of the rest were more like showing agreement with or acknowledging other students' opinions. The challenging label was correctly used all the time, but it was the most infrequently used label. Later analysis revealed that students used at least one strategy in 29 of the 39 posts that were not labeled. No strategy use was observed in only 10 posts.

Table 3 Numbers and Proportions of Labeled Posts in the Final Module, Section B $(n=17)$

\begin{tabular}{lrlrl}
\hline Label used & \multicolumn{2}{c}{ Posts using labels } & \multicolumn{2}{c}{ Posts correctly labeled } \\
\hline & $n$ & Proportion & \multicolumn{1}{l}{ Proportion } \\
Elaborating and clarifying & 10 & 0.11 & 7 & 0.70 \\
Making connections & 18 & 0.19 & 16 & 0.89 \\
Challenging & 3 & 0.03 & 3 & 1.00 \\
Building & 14 & 0.15 & 9 & 0.64 \\
Questioning & 9 & 0.10 & 8 & 0.89 \\
No label used & 39 & 0.42 & & \\
\hline Total & 93 & 1.00 & & \\
\hline
\end{tabular}




\section{Student Use of Strategies}

Student actual use of strategies was analyzed, regardless of how they were labeled. Table 4 shows the frequencies of strategy use in the introduction and final modules for students in both sections.

Table 4 Means (Standard Deviations) of Frequencies of Individual Student's Strategy Use in Both Sections (n = 22 in Section A; $n=17$ in Section B)

\begin{tabular}{|c|c|c|c|c|}
\hline & \multicolumn{2}{|c|}{ Introduction unit } & \multicolumn{2}{|c|}{ Final module } \\
\hline & Section A & Section B & Section A & Section B \\
\hline Strategy 1: EC ${ }^{a^{*}}$ & $2.12(1.45)$ & $2.14(1.17)$ & $2.29(1.31)$ & 3.41 (1.59) \\
\hline Strategy 2: MC ${ }^{\mathrm{b}^{*}}$ & $1.23(.75)$ & $1.12(.99)$ & $1.32(1.04)$ & $2.24(1.44)$ \\
\hline Strategy 3: $\mathrm{CH}^{\mathrm{c}^{*}}$ & $.95(.90)$ & $.88(.93)$ & $.27(.55)$ & $.82(1.07)$ \\
\hline Strategy 4: BLD ${ }^{d}$ & $.95(.84)$ & $1.24(1.25)$ & $1.14(1.46)$ & $.88(1.05)$ \\
\hline Strategy 5: QST $\mathrm{e}^{* *}$ & $.18(.39)$ & .18 ( . .39) & $.27(.55)$ & $1.00(.79)$ \\
\hline
\end{tabular}

${ }^{\mathrm{a}}$ Elaborating and clarifying. ${ }^{\mathrm{b}}$ Making connections. ${ }^{\mathrm{c}}$ Challenging. ${ }^{\mathrm{d}}$ Building. ${ }^{\mathrm{e}}$ Questioning. $* p<.05 ;{ }^{* *} p<.005$

The result of MANOVA showed a statistically significant difference in the number of strategies used by students in the two sections $(p<.001$, power $=.967)$. The test of between-subject effects revealed further information: When controlling for the difference in strategy use in the introduction unit across the two conditions, there were group effects for Strategy 1 (elaborating and clarifying) $(p<.05$, power $=.654)$, Strategy 2 (making connections) $(p<.05$, power $=.578)$, Strategy 3 (challenging) $(p<.05$, power $=.512$ ), and Strategy 5 (questioning) $(p<.005$, power $=.910)$. This suggests that compared to the students in Section A the students in Section B used more of Strategies 1, 2, 3, and 5 in the final module. There was no significant difference in the use of Strategy 4 (building). Running MANOVA on the proportions of strategy use led to the same results.

\section{Quality of Discussion}

To judge the quality of discussions, student posts were analyzed according to Gunawardena, Lowe, and Anderson's (1997) interaction analysis model. Table 5 presents the means and standard deviations of the number of student posts that showed the characteristics of the five phases in the model, and Table 6 presents the total number of posts that demonstrated the characteristics of the five phases. Because one post can be coded into multiple categories (Gunawardena, et al., 1997), the sum of the posts under the five phases is greater than the total number of posts.

Table 5 Means (Standard Deviations) of Frequencies of Individual Students' Posts Showing the Characteristics of the Five Phases in Both Sections ( $n=22$ in Section A; $n=17$ in Section B)

\begin{tabular}{|c|c|c|c|c|}
\hline & \multicolumn{2}{|c|}{ Introduction unit } & \multicolumn{2}{|c|}{ Final module } \\
\hline & Section A & Section B & Section A & Section B \\
\hline Phase I* & $2.47(1.42)$ & $1.86(.99)$ & $2.24(1.35)$ & $3.36(1.92)$ \\
\hline Phase II* & $.77 \quad(.87)$ & $.53(.72)$ & $.91 \quad(.92)$ & 1.53 (1.18) \\
\hline Phase III & $(.65)$ & $.41(.62)$ & $.32 \quad(.57)$ & .88 (.99) \\
\hline Phase IV & $(.00)$ & $.00(.00)$ & $.00 \quad(.00)$ & $.06 \quad(.24)$ \\
\hline Phase V & $(.21)$ & $.06(.24)$ & $.09 \quad(.29)$ & $.14 \quad(.44)$ \\
\hline
\end{tabular}

$* p<.05$ 
Table 6 Total Number of Posts Showing the Characteristics of the Five Phases in Both Sections $(n=22$ in Section A; $n=17$ in Section B)

\begin{tabular}{lllll}
\hline & \multicolumn{2}{l}{ Introduction unit } & \multicolumn{2}{l}{ Final module } \\
\hline & Section A & Section B & Section A & Section B \\
Phase I* & 54 & 32 & 49 & 57 \\
Phase II* & 17 & 9 & 20 & 26 \\
Phase III & 7 & 7 & 7 & 15 \\
Phase IV & 0 & 0 & 0 & 1 \\
Phase V & 1 & 1 & 2 & 2 \\
\hline
\end{tabular}

No significant difference was observed in the introduction unit, so MANOVA was conducted to see if there was a significant difference in student performance in the final module. The result revealed an overall effect of group $(p<.05$, power $=.817)$, and the follow-up tests of between-subject effects suggested a statistically significant increase in Phase I $(p<.05$, power $=.682)$ and Phase II $(p<.05$, power $=.508)$. This implied the intervention had a positive effect on increasing the posts in Phase I and Phase II. But there was no significant increase in Phase III-V. Table 6 shows that, similar to what Gunawardena et al. (1997) found in their research, the number of posts coded into Phases I and II (e.g., 83 posts in the final module of Section B) is much larger than those coded into Phases III to V (e.g., 18 posts in the final module of Section B). This suggests that the intervention had an impact on those phases with the majority of posts.

\section{Survey of Student Perceptions}

The means and standard deviations of survey responses are presented in Table 7. The ratings to all the 10 items have medians of 1 . Except for Item 7, the other nine items have modes of 1, suggesting that around $50 \%$ of the students chose agree (denoted as 1 ) as their responses. Around $30 \%$ of the students provided their answers as strongly agree. The consistent results among mean, median, and mode suggested that almost all of the students believed that the instruction had a positive impact on their online discussion. There is no surprise when MANOVA revealed statistically significant positive responses to all 10 items $(p<.05)$. Table 7 Means and Standard Deviations of Survey Items $(n=17)$

\begin{tabular}{lr}
\hline \multicolumn{1}{c}{ Survey items } & Mean (SD) \\
\hline Using online discussion strategies and labels helps me & \\
1. state my own thoughts more clearly & $.93(.997)^{*}$ \\
2. support my own thoughts with more solid evidence and & $.86(1.027)^{*}$ \\
reasoning & $1.14(1.027)^{*}$ \\
3. pay more attention to other people's views & $.86(1.167)^{*}$ \\
4. evaluate and compare other people's views more critically & $.86(1.027)^{*}$ \\
5. learn more from other people's views & $1.14(.770)^{*}$ \\
6. make more connections among different views & $.64(1.082)^{*}$ \\
7. develop a solid understanding of the issue discussed & $.93(.997)^{*}$ \\
8. engage more fully in the online discussion & $.86(1.027)^{*}$ \\
9. interact more actively with other students & $.86(1.027)^{*}$ \\
10. feel more confident about participating in online discussion & \\
\hline
\end{tabular}

$* \mathrm{p}<.05$ 


\section{Student Online Comments}

Though it was not required by the instructor, 15 out of 17 students in Section B commented at least once on their experiences of using labels and strategies in the separate forum. All of them expressed that the intervention was helpful. Three major themes were identified in the comments, as is shown in Table 8.

In general, many (11 students) believed that using labels and strategies helped them organize their thoughts and communicate more effectively. Nine students also felt that the intervention helped establish expectations and a common ground for discussions, so that they knew what to expect and what was expected from them. There were three comments, however, showing some concerns about this approach: One student wrote that it was hard for her to differentiate between elaborating and clarifying and making connections. This was echoed by a comment from another student, who said, "It can be difficult sometimes to determine which label to choose for your post." In addition, one student expressed the concern that she felt it difficult to challenge other people's views in the online environment.

Table 8 Major Themes Identified From Student Comments $(n=17)$

\begin{tabular}{|c|c|c|}
\hline Major themes & Examples & Number \\
\hline $\begin{array}{l}\text { The approach } \\
\text { facilitated the } \\
\text { process of }\end{array}$ & $\begin{array}{l}\text { "I really enjoy learning those discussion strategies. It's helping me } \\
\text { to organize my thoughts in a more structured fashion, which in } \\
\text { turn, makes the learning process more effective." }\end{array}$ & 11 \\
\hline $\begin{array}{l}\text { and } \\
\text { communication. }\end{array}$ & $\begin{array}{l}\text { "I have found the mini-lectures to be very helpful! By having to } \\
\text { choose whether I was 'elaborating and clarifying' or 'making } \\
\text { connections', I was able to re-think what I was posting and the } \\
\text { message I was trying to get across. It allows me to evaluate my } \\
\text { questions and comments to make sure I am contributing } \\
\text { appropriately to the discussion!" }\end{array}$ & \\
\hline \multirow[t]{2}{*}{$\begin{array}{l}\text { The approach } \\
\text { helps set up } \\
\text { expectations and } \\
\text { norms for the } \\
\text { online discussions. }\end{array}$} & $\begin{array}{l}\text { "It's nice that the challenging aspects of discussion have been laid } \\
\text { out as an expected objective, rather than optional because then } \\
\text { those who haven't had on-line experiences won't be offended when } \\
\text { their comments are approached in this manner." }\end{array}$ & 9 \\
\hline & $\begin{array}{l}\text { "In past on-line courses, where no guidelines were provided, the } \\
\text { discussion forums would lose their effectiveness, I believe. The } \\
\text { discussion threads were incoherent and the conversations were } \\
\text { confusing because we (the students) lacked direction or guidance. I } \\
\text { appreciate the discussion strategies and labels because they help } \\
\text { me decide if my ideas and thoughts are really relevant to the } \\
\text { discussion." }\end{array}$ & \\
\hline \multirow[t]{2}{*}{$\begin{array}{l}\text { Concerns or } \\
\text { confusion }\end{array}$} & $\begin{array}{l}\text { "I sometimes have difficulty differentiating between 'elaborating } \\
\text { and clarifying' and 'making connections'. I feel there's a great deal } \\
\text { of overlap. Does anyone else feel this way?" }\end{array}$ & 3 \\
\hline & $\begin{array}{l}\text { "Reading that one of the discussion strategies for this Module is } \\
\text { 'Challenging Others' View,' put me in a panic. I am usually up to a } \\
\text { good debate when face-to-face, however, I find myself very } \\
\text { uncomfortable having to challenge someone online. Not sure } \\
\text { why...maybe because I'm just afraid I'll offend someone and not } \\
\text { know it. Whereas, if I'm speaking face-to-face I have the advantage } \\
\text { of observing body language, tone, etc. to clue me in on how the } \\
\text { conversation is going...” }\end{array}$ & \\
\hline
\end{tabular}




\section{Discussion}

Both the analysis of student strategy use and the survey on student perceptions suggested potentially positive effects of the intervention, which entailed teaching and labeling discussion strategies. The study, however, also raised a few concerns regarding this approach. Here are the major findings.

First, students in Section B used labels extensively after the intervention. Among 93 posts, 54 were labeled, suggesting a wide adoption of the labeling approach. There were, however, times when the labels were used incorrectly, indicating that some students might not have fully grasped how to use certain strategies though they intentionally tried to use them. This was especially true for the Strategy 4 (building)-36\% of the posts labeled as building were actually showing agreements with or acknowledgements of others' opinions. There is probably a need for the instructor to provide more explicit explanation on how this strategy differs from showing agreements and demonstrate the differences with examples.

The analysis suggests that 39 posts of the total of 93 posts were not labeled, but only 10 posts did not demonstrate the use of any strategies. In other words, the number of posts that were identified as using at least one strategy was much higher than the number of posts that were labeled. Multiple reasons may contribute to this result. It is possible that sometimes students used certain strategies but forgot to label the posts despite being reminded to do so. Or they might have chosen not to use the labels because it was difficult to determine which post type they were to use. It also possible that some students did not fully understand the instruction and were not sure when or how to use these strategies. Understanding the reasons behind why some students did not label their posts despite using one or more of the strategies may provide insights into how to improve the effectiveness of the proposed approach. In this sense, future research should consider conducting in-depth interviews with participants to gain a better understanding of why they decided to use or not to use the post type labels.

Second, compared to those in the control group, students in the experimental group used more strategies after the intervention. Except for Strategy 4 (building), the frequencies and proportions of all the other strategies increased significantly after the intervention, indicating that the use of discussion strategies and labels can be an effective approach to encourage the desired types of posts in online discussions. The analysis also showed that the degree of increase was uneven. The use of Strategy 5 (questioning) had the greatest change, showing an average increase of .82 in Section B as compared to an increase of .09 in Section A. This might imply that questioning was a strategy that students might not naturally think of using on their own. But when taught by the instructor, students could easily adopt it in the discussions. As for other strategies, such as elaborating and clarifying, making connections, and challenging, it might take students more time and more practice to master them. Strategy 3 (challenging) was rarely used despite the intervention. One possible reason could be that students felt uncomfortable challenging their peers in online discussions, even though they were explicitly encouraged by the instructor to do so. This concern was expressed by one student: "Reading that one of the discussion strategies for this Module is 'Challenging Others' View' put me in a panic. I am usually up to a good debate when face-to-face, however, I find myself very uncomfortable having to challenge someone online. Not sure why...maybe because I'm just afraid I'll offend someone and not know it. Whereas, if I'm speaking face-to-face I have the advantage of observing body language, tone, etc. to clue me in on how the conversation is going." It is worth noting that the majority of the participants were females, and according to Guiller and Durndell (2006), females were more likely than males to be supportive and express agreement.

Third, the quality of posts was examined using Gunawardena, Lowe, and Anderson's (1997) interaction analysis model. Though the analysis suggested an increase of the posts in Phases I and II, there was no significantly increase of posts in Phases III to V. There are a few possible explanations. First, 
Gunawardena et al.'s model was developed based on the analysis of learners' posts in an online debate. As a result, some of the behaviors described in the higher phases of Gunawardena et al.'s model, such as testing and modification of proposed synthesis, may not be as commonly seen in the discussions, where students were asked to share and make connections to their own personal experiences to develop a better understanding of the learning theories. Second, the focus of this particular study was the five basic online discussion strategies. Some other strategies, which are also important and may lead to behaviors described in the higher phases of the model, such as synthesizing, were not explicitly taught. As a result, there is little increase in those types of behaviors.

Finally, the survey results revealed that students had positive attitudes toward the intervention. They felt they were able to pay more attention to other people's views and make more connections to different views. The comments they wrote expressed their enthusiasm for using the labels and strategies. One student said, "I wanted to say that I too have learned a lot from the mini lessons. I wish that I had this information seven online classes ago!” The survey results and student online comments suggested that students believed that they benefited from the use of labels and strategies.

\section{Limitations and Future Research}

The study draws upon previous research on constrained discussion environments and strategy instruction, and develops a new instructional approach to promote quality discussion online. This particular approach combines online discussion strategy instruction with the use of post type labels. The findings of the study suggest that the approach increased student use of the desired strategies, positively impacted student perceived learning experience, and improved certain aspects of the quality of the online discussions.

The study has a few limitations. First, the participants in the study were not randomly assigned to two different sections, so this is not a strict experimental study. As a result, the findings of the study still need to be interpreted with caution. Second, the study mainly focused on the process of learning by examining the use of labels and strategies as well as the quality of discussion. The learning outcome was not measured. So it is uncertain whether the discussions had led to enhanced learning. Future studies that measure the learning outcomes are needed to better understand the value of this approach.

The findings of the study suggest a few directions for future research. First, the study raised the question of what strategies should be taught and under what circumstances. Certain online discussion strategies are quite generic and can be used in most online discussions regardless of the discussion topics, as those taught in this study. There are times, however, when students need to be taught specific types of strategies depending on the purposes of discussion or learning. For example, participating in online argumentation may require students to know how to make counterclaims or rebuttals. When researchers and instructors make decisions on which discussion strategy to teach, they should consider whether the set of discussion strategies selected are appropriate for the learning tasks at hand.

Second, future studies should explore how instructors could better encourage and support students to use the strategy of challenging/critiquing when necessary. Student comments revealed that fostering a safe and honest learning community was essential for students to feel comfortable doing so. In fact, some researchers have examined the effects of having debates on controversial issues on increasing the amount of challenging and critiquing posts. What they found was that although online debates encouraged participants to spend more time on arguing and elaborating on what others had stated, participants rarely critiqued and evaluated each other's ideas (Davidson-Shivers et al., 2012). So, will it help if we teach students to use the challenging strategy and label and then have them practice it in an online debate? The combination of both approaches might have a chance to increase the quantity and quality of challenging posts in the discussion. 
Third, the results of the study reveal that, on some occasions, students found it hard to differentiate the strategies or to choose the right labels. This result is understandable because a student could use more than one strategy when composing a post, and in some cases the strategies are intertwined. Having students choose a single strategy label for a post may benefit them at the initial stage of learning, because this allows them to focus on learning and practicing one discussion strategy at a time. However, a good post often requires an effective use of more than one strategy. That means students also need to know how to use a combination of two or more strategies in one single post. Will students naturally be able to do this when they have mastered each individual strategy? Or do they need additional instruction or scaffolding to achieve it? And if so, how should instructors provide such scaffolding? These are the questions worth exploring in future studies.

Based on the discussion above, here are a few suggestions for instructors who may consider adopting this approach in their own online classes. First, when making decisions about discussion strategies to be taught, instructors need to make sure that the strategies chosen are aligned with the learning tasks. At the same time, one discussion task may be more suitable than another when it comes to learning a particular discussion strategy. Carefully choosing the discussion strategies to be taught and pairing them with the appropriate discussion tasks may help students learn in a more efficient way. Second, in this study, the instructor modeled the strategy use and provided general feedback to the whole class but did not intervene the discussions by pointing out what needs to be improved for each individual student. The results suggested, however, that some of the students did not fully grasp the strategies taught. As a result, when implementing this approach in the future, instructors may need to consider providing timely feedback to individual students regarding how well they use the strategies and labels.

\section{References}

An, H., Shin, S., \& Lim, K. (2009). The effects of different instructor facilitation approaches on students' interactions during asynchronous online discussions. Computers \& Education, 53(3), 749-760. doi: 10.1016/j.compedu.2009.04.015

Anderson, T. (1996). The virtual conference: Extending professional education in cyberspace. International Journal of Educational Telecommunications, 2, 121-135.

Berge, Z. L., \& Muilenburg, L. (2002). Questions for online, adult learning. In A. Rossett (Ed.), The ASTD E-learning handbook: Best practices, strategies and case studies for an emerging field (pp. 183-190). Chicago: McGraw-Hill Professional.

Bradley, M. E., Thom, L. R., Hayes, J., \& Hay, C. (2008). Ask and you will receive: How question type influences quantity and quality of online discussions. British Journal of Educational Technology, 39(5), 888-900.

Brookfield, S. D., \& Preskill, S. (1999). Keeping discussion going through questioning, listening, and responding. Discussion as a way of teaching: Tools and techniques for democratic classrooms (pp. 85-102). San Fransisco: Jossey-Bass.

Brown, R., Pressley, M., Van Meter, P., \& Schuder, T. (1996). A quasi-experimental validation of transactional strategies instruction with low-achieving second grade readers. Journal of Educational Psychology, 88, 18-37.

Capozzoli, M., McSweeney, L., \& Sinha, D. (1999). Beyond kappa: A review of interrater agreement measures. The Canadian Journal of Statistics, 27(1), 3-23.

Chamot, A. U. (2005). Language learning strategy instruction: Current issues and research. Annual Review of Applied Linguistics, 25, 112-130. doi: 10.1017.S0267190505000061 
Chiu, C.-H., Wu, C.-Y., Hsieh, S.-J., Cheng, H.-W., \& Huang, C.-K. (2013). Employing a structured interface to advance primary students' communicative competence in a text-based computer mediated environment. Computers \& Education, 60(1), 347-356. doi: http://dx.doi.org/10.1016/j.compedu.2012.09.002

Choi, H. J., \& Johnson, S. D. (2005). The effect of context-based video instruction on learning and motivation in online courses. American Journal of Distance Education, 19(4), 215-227.

Choi, I., Land, S. M., \& Turgeon, A. (2008). Instructor modeling and online question prompts for supporting peer-questioning during online discussion. Journal of Educational Technology Systems, 36(3), 255-275. doi: 10.2190/ET.36.3.c

Choi, I., Land, S. M., \& Turgeon, A. J. (2005). Scaffolding peer-questioning strategies to facilitate metacognition during online small group discussion. Instructional Science, 33, 483-511.

Collison, G., Elbaum, B., Haavind, S., \& Tinker, R. (2000). Facilitating online learning: Effective strategies for moderators. Madison, WI: Atwood Publishing.

Davidson-Shivers, G. V., Luyegu, E., \& Kimble, B. E. (2012). An analysis of asynchronous discussions: A case study of graduate student participation in online debates. Journal of Educational Multimedia and Hypermedia, 21(1), 29-51.

Deshler, D. D., \& Schumaker, J. B. (1988). An instructional model for teaching students how to learn. In J. L. Graden, J. E. Zins, \& M. J. Curtis (Eds.), Alternative educational delivery systems: Enhancing instructional options for all students. Washington, DC: National Association of School Psychologists.

Deshler, D. D., Schumaker, J. B., Lenz, B. K., \& Ellis, E. (1984). Academic and cognitive interventions for LD adolescents. Journal of Learning Disabilities, 17, 108-117.

Dillon, J. T. (1984). Research on questioning and discussion. Educational Leadership, 42(3), 50-56.

Duffy, G. G., \& Roehler, L. (1987). Improving reading instruction through the use of responsive elaboration. The Reading Teacher, 40, 514-520.

Duffy, G. G., \& Roehler, L. (1989). Improving classroom reading instruction: A decision-making approach (2nd ed.). New York: Random House.

Ertmer, P. A., Richardson, J. C., Belland, B., Camin, D., Connolly, P., Coulthard, G., . . Mong, C. (2007). Using peer feedback to enhance the quality of student online postings. Journal of Computer Mediated Communication, 12(2), 412-433.

Gao, F., Wang, C. X., \& Sun, Y. (2009). A new model of productive online discussion and its implication for research and discussion. The Journal of Educational Technology Development and Exchange, 2(1), 65-78.

Gilbert, P. K., \& Dabbagh, N. (2005). How to structure online discussions for meaningful discourse: A case study. British Journal of Educational Technology, 36(1), 5-18. doi: 10.1111/j.14678535.2005.00434.x

Graham, S. (2006). Strategy instruction and the teaching of writing: A meta-analysis. In C. A. MacArthur, S. Graham, \& J. Fitzgerald (Eds.), Handbook of writing research (pp. 187-207). New York: Guilford.

Gunawardena, C. N., Lowe, C. A., \& Anderson, T. (1997). Analysis of a global on-line debate and the development of an interaction analysis model for examining social construction of knowledge in computer conferencing. Journal of Educational Computing Research, 17(4), 397-431. 
Guzdial, M., \& Turns, J. (2000). Effective discussion through a computer-mediated anchored forum. The Journal of the Learning Sciences, 9(4), 437-469.

Hara, N. M., Bonk, C. J. M., \& Angeli, C. M. (2000). Content analysis of online discussion in an applied educational psychology course. Instructional Science, 28, 115-152.

Hoadley, C., \& Linn, M. (2000). Teaching science through online peer discussions: SpeakEasy in the knowledge integration environment. International Journal of Science Education, 22, 839-857.

Hock, M. F., \& Mellard, D. F. (2011). Efficacy of learning strategies instruction in adult education. Journal of Research on Educational Effectiveness, 4(2), 134-153. doi: 10.1080/19345747.2011.555291

Jeong, A., \& Joung, S. (2007). Scaffolding collaborative argumentation in asynchronous discussions with message constraints and message labels. Computers and Education, 48(3), 427-445.

Joeng, A. (2003). Sequential analysis of group interaction and critical thinking in threaded discussions. The American Journal of Distance Education, 17(4), 397-413.

Johnson, G. M. (2006). Online study groups: Reciprocal peer questioning versus mnemonic devices. Journal of Educational Computing Research, 35(1), 83-96.

Jonassen, D. H. (1991). Evaluating constructivistic learning. Educational Technology, 28(11), 13-16.

Jonassen, D. H., Davidson, M., Collins, M., Compbell, J., \& Hagg, B. B. (1995). Constructivism and computer-mediated communication in distance education. The American Journal of Distance Education, 9, 7-26.

Jonassen, D. H., \& Kim, B. (2010). Arguing to learn and learning to argue: Design justifications and guidelines. Educational Technology Research \& Development, 58(4), 439-457. doi: 10.1007/s11423-009-9143-8

Jonassen, D. H., \& Remidez, H. (2005). Mapping alternative discourse structures onto computer conferences. International Journal of Knowledge and Learning, 1(1/2), 113-129.

Kanuka, H., \& Anderson, T. (1998). Online social interchange, discord and knowledge construction. Journal of Distance Education, 13(1), 57-74.

King, A. (1990). Enhancing peer interaction and learning in the classroom through reciprocal questioning. American Educational Research Journal, 27(4), 664-687.

King, A. (1991). Effects of training in strategic questioning on children's problem solving performance. Journal of Educational Psychology, 83(3), 307-317.

King, A., \& Rosenshine, B. (1993). Effects of guided cooperative questioning on children's knowledge construction. Journal of Experimental Education, 61, 127-148.

Larson, B. E., \& Keiper, T. A. (2002). Classroom discussion and threaded electronic discussion: Learning in two arenas. Contemporary Issues in Technology and Teacher Education, 2(1), 45-62.

MacArthur, C. A., \& Lembo, L. (2009). Strategy instruction in writing for adult literacy learners. Reading \& Writing, 22(9), 1021-1039. doi: 10.1007/s11145-008-9142-X

Mellard, D. D. (2006). Feasibility of explicit instruction in adult basic education: Instructor-learner interaction patterns. Adult Basic Education, 16(1), 21-37.

Moore, J. L., \& Marra, R. M. (2005). A comparative analysis of online discussion participation protocols. Journal of Research on Technology in Education, 38(2), 191-212.

Nussbaum, E. M. (2005). The effect of goal instructions and need for cognition on interactive argumentation. Educational Contemporary Psychology, 30(3), 286-313. 
Nussbaum, E. M., Hartley, K., Sinatra, G. M., Reynolds, R. E., \& Bendixen, L. D. (2004). Personality interactions and scaffolding in on-line discussions. Journal of Educational Computing Research, 30, 113-136.

Oh, S., \& Jonassen, D. H. (2007). Scaffolding online argumentation during problem solving. Journal of Computer Assisted Learning, 23(2), 95-110. doi: 10.1111/j.1365-2729.2006.00206.x

Oztok, M., Zingaro, D., Brett, C., \& Hewitt, J. (2013). Exploring asynchronous and synchronous tool use in online courses. Computers \& Education, 60(1), 87-94. doi: http://dx.doi.org/10.1016/j.compedu.2012.08.007

Palinscar, A. S., \& Brown, A. L. (1984). Reciprocal teaching of comprehension-fostering and monitoring activities. Cognition and Instruction, 2, 117-175.

Pressley, M. (1986). The relevance of the good strategy user model to the teaching of mathematics. Educational Psychologist, 21, 139-161.

Pressley, M., \& Woloshyn, V. (1990). Cognitive strategy instruction that really improves children's academic performance. Cambridge, Mass: Brookline Books.

Pressley, M., Wood, E., Woloshyn, V. E., \& Martin, V. (1992). Encouraging mindful use of prior knowledge: Attempting to construct explanatory answers facilitates learning. Educational Psychologist, 27, 91-109.

Rourke, L., \& Kanuka, H. (2009). Learning in communities of inquiry: A review of the literature. Journal of Distance Education, 23(1), 19-48.

Scardamalia, M., \& Bereiter, C. (1994). Computer support for knowledge-building communities. The Journal of the Learning Sciences, 3(3), 265-283.

Scheuer, O., McLaren, B., Weinberger, A., \& Niebuhr, S. (2013). Promoting critical, elaborative discussions through a collaboration script and argument diagrams. Instructional Science, 1-31. doi: 10.1007/s11251-013-9274-5

Schumaker, J., \& Deshler, D. (2006). Teaching adolescents to be strategic learners. In D. Deshler \& J. Schumaker (Eds.), Teaching adolescents with disabilities: Accessing the general education curriculum (pp. 121-156). New York: Corwin.

Seo, K. K. (2007). Utilizing peer moderating in online discussions: Addressing the controversy between teacher moderation and nonmoderation. American Journal of Distance Education, 21(1), 21-36.

Thomas, J. (2013). Exploring the use of asynchronous online discussion in health care education: A literature review. Computers \& Education, 69(0), 199-215. doi: http://dx.doi.org/10.1016/j.compedu.2013.07.005

Thomas, M. J. W. (2002). Learning within incoherent structures: The space of online discussion forums. Journal of Computer Assisted Learning, 18, 351-366.

Tsai, P.-S., \& Tsai, C.-C. (2013). College students' experience of online argumentation: Conceptions, approaches and the conditions of using question prompts. The Internet and Higher Education, 17(0), 38-47. doi: http://dx.doi.org/10.1016/j.iheduc.2012.10.001

Wegmann, S., \& McCauley, J. (2008). Shouting through the fingertips: Computer-mediated discourse in an asynchronous environment. In K. McFerrin et al. (Eds.), Proceedings of Society for Information Technology and Teacher Education International Conference (pp. 805-808). Chesapeake, VA: AACE.

Weinstein, C. E., \& Mayer, R. E. (1986). The teaching of learning strategies. In M. C. Wittrock (Ed.), Handbook of research on teaching (pp. 315-327). New York: Macmillan. 
Yang, Y. C., Newby, T. J., \& Bill, R. L. (2005). Using Socratic questioning to promote critical thinking skills through asynchronous discussion forums in distance learning environments. The American Journal of Distance Education, 19(3), 163-181.

Zydney, J. M., deNoyelles, A., \& Seo, K.-J. K. (2012). Creating a community of inquiry in online environments: An exploratory study on the effect of a protocol on interactions within asynchronous discussions. Computers \& Education, 58(1), 77-87. doi: http://dx.doi.org/10.1016/j.compedu.2011.07.009

\section{Appendix}

Appendix 1. An Example of Discussion Strategy Instruction

Here is an example of how the strategy of elaborating and clarifying was introduced to the students in a mini-lecture. The mini-lecture started with common problems when having online discussions:

To appropriately state your own thought is always the first step toward a productive discussion. The problems we usually see in not very good discussions are: (a) the participant states his/her opinions in only one or two short sentences without sufficient elaboration on what they mean by it; (b) the participant writes about different issues and jumps from one thought to another, which makes it hard to follow his/her reasoning and logic; (b) Sometimes, a point is made, but little relation can be found between what the participant has said and the topic under discussion. In this lecture, we will introduce two discussion strategies that aim at solving such problems in discussion. The first one is elaborating and clarifying.

Then, the strategy was introduced:

\section{Discussion Strategy I: Elaborating and Clarifying}

When you are stating your opinions in a posting, you will need to make your point clear and easy to understand by others. If the idea you are presenting is complex or abstract, you will probably need to elaborate on your idea. There are several ways to make a clear and elaborative point:

a. Use concrete examples or metaphors to illustrate an abstract idea;

b. Draw on evidence from your personal experiences, from what you have read from book or what you have learned from others to support your point. Attention: Please understand if you refer to your experience or quotation, you are using it to illustrate your idea. So provide your analytical or reflective thoughts of the experience or quotation.

c. Make clear your logic or reasoning of how you get to this point. This will make your postings more explicit, coherent, and persuasive to others.

When you finish your posting, go through this checklist. If you have successfully addressed all the questions below, you probably have done a good job of elaborating and clarifying your opinions.

Checklist for elaborating and clarifying:

- Why am I saying so?

- When I say this, what does that mean?

- $\quad$ Is my point well supported by certain theory/evidence?

- $\quad$ Am I presenting my argument in a logic and reasonable way?

Finally, instruction was given on how to use the post type labels along with the strategies when they were having discussions: 
Task: In this week's discussion, you are supposed to try the strategy in your discussion forum. When you go to the page of posting a new message, you will see 'post type' right under 'subject.' Click on the pull-down menu of post type, you will see you are able to choose 'none' or a particular strategy. So, if you are using the strategy of elaborating and clarifying, please choose 'Elaborating and Clarifying' as your post type. If you think you are using more than one strategy, choose the one you think most evident in your post. Leave the post type to 'none' if you are not using any strategies in your posting."

When students started the discussions, the instructor modeled the newly taught strategies a few times. Here is an example of the instructor modeling the use of elaborating and clarifying:

You raised an interesting question. What can we do to help others, such as our children or our students, become more motivated? From my opinion, in addition to teaching kids things that they feel useful and interesting, modeling your passion to your students is important. Let your students see what you are passionate about. If possible, find times when you can talk about your passion and share it with your students. I can still recall those Friday afternoons when my elementary teacher read aloud the poems she loved to us. Everyone in the classroom was attracted by the beautiful rhythms and the world full of imagination. That was when I started to understand poems and become a passionate reader of poems myself. 